\title{
Electromagnetic Design of High-Power and High-Speed Permanent Magnet Synchronous Motor Considering Loss Characteristics
}

\author{
Wen Ji ${ }^{1}$, Fei Ni ${ }^{2, *(D)}$, Dinggang Gao ${ }^{2}$, Shihui Luo ${ }^{1}$, Qichao $\mathrm{Lv}^{3,4}$ and Dongyuan $\mathrm{Lv}^{3,4}$ \\ 1 Traction Power State Key Laboratory, Southwest Jiaotong University, Chengdu 610031, China; \\ 12191@tongii.edu.cn (W.J.); shluo@swjtu.cn (S.L.) \\ 2 Maglev Transportation Engineering R\&D Center, Tongji University, Shanghai 201804, China; \\ 12138@tongi.edu.cn \\ 3 Shanghai Aerospace Control Technology Institute, Shanghai 201109, China; qichao201@163.com (Q.L.); \\ lvdongyuan1990@163.com (D.L.) \\ 4 Shanghai Space Intelligent Control Technology Key Laboratory, Shanghai 201109, China \\ * Correspondence: fei.ni@tongji.edu.cn; Tel.: +86-21-6958-0338
}

Citation: Ji, W.; Ni, F.; Gao, D.; Luo, S.; Lv, Q.; Lv, D. Electromagnetic Design of High-Power and High-Speed Permanent Magnet Synchronous Motor Considering Loss Characteristics. Energies 2021, 14, 3622. https://doi.org/10.3390/ en14123622

Academic Editor: Jin-Woo Ahn

Received: 21 April 2021

Accepted: 15 June 2021

Published: 18 June 2021

Publisher's Note: MDPI stays neutral with regard to jurisdictional claims in published maps and institutional affiliations.

Copyright: (c) 2021 by the authors. Licensee MDPI, Basel, Switzerland. This article is an open access article distributed under the terms and conditions of the Creative Commons Attribution (CC BY) license (https:/ / creativecommons.org/licenses/by/ $4.0 /)$.

\begin{abstract}
The motor is an important part of the flywheel energy storage system. The flywheel energy storage system realizes the absorption and release of electric energy through the motor, and the highperformance, low-loss, high-power, high-speed motors are key components to improve the energy conversion efficiency of energy storage flywheels. This paper analyzes the operating characteristics of the permanent magnet synchronous motor/generator (PMSG) used in the magnetically levitated flywheel energy storage system (FESS) and calculates the loss characteristics in the drive and power generation modes. Based on this, the electromagnetic part of the motor is optimized in detail. Aiming at this design, this paper calculates the loss characteristics of driving and power generation modes in detail, including its winding loss, core loss, rotor eddy current loss and mechanical loss. The calculation results show that the design meets the loss requirements. It can reduce the no-load loss of the permanent magnet synchronous motor at high speed and improve the energy conversion efficiency, which gives this system practical application prospects.
\end{abstract}

Keywords: magnetic levitation flywheel energy storage system; permanent magnet synchronous motor; electromagnetic design; loss characteristics

\section{Introduction}

The flywheel energy storage system is an energy storage device that converts electrical energy and mechanical energy with a high-speed rotating flywheel rotor as a carrier [1], and it is one of the preferred solutions for short-term energy storage systems. The flywheel energy storage system mainly has three working modes: charging, standby and discharging. When the flywheel energy storage system is charging, the motor runs electrically. It drives the flywheel rotor to accelerate to a specified speed and converts electrical energy into flywheel kinetic energy for storage. When the flywheel energy storage system is in standby, the flywheel runs at a specified speed without load. When the flywheel energy storage system discharges, the flywheel decelerates and drives the motor to generate electricity. It uses the flywheel controller to convert the kinetic energy of the flywheel into electrical energy and release it.

The motor is an important part of the flywheel energy storage system. The flywheel energy storage system realizes the absorption and release of electric energy through the motor. The performance of the flywheel energy storage system obtained by using different flywheel motors is also different. The requirements of the flywheel energy storage system for the motor are: it can work in the state of electric and power generation; it has good high-speed performance, high efficiency, low no-load loss, small size, low noise, simple 
structure, easy maintenance, etc. The motors currently used in flywheel energy storage systems mainly include asynchronous motors, switched reluctance motors, permanent magnet brushless DC motors, and permanent magnet synchronous motors [2]. Each motor has its own structural characteristics. They have their own advantages and disadvantages in flywheel energy storage systems [3,4] Asynchronous motors (also called induction motors) are widely used. It has mature manufacturing technology, sturdiness and durability, small maintenance workload and low manufacturing cost. However, the motor has low efficiency, low power factor, and needs to absorb reactive power from the outside when generating electricity. Therefore, asynchronous motors are generally used in low-speed and large-capacity flywheel energy storage systems. Switched reluctance motors have the advantages of simple structure, sturdiness, high temperature resistance, low cost and reliable operation. However, the switched reluctance motor has large torque pulsation and high noise, and its operation must rely on sensors to obtain the rotor position signal, which increases the complexity of the system. Permanent magnet brushless DC motors have similar performance advantages as DC motors: easy to start, wide speed range, simple control and easy to achieve two-way power flow. However, permanent magnets are easy to demagnetize and demagnetize at high temperatures, and the motor must rely on position sensors for current commutation. The square wave of stator current also makes its harmonic components high and torque ripple large.

Comparing to above mentioned types, permanent magnet synchronous motors are widely used in high-speed flywheel energy storage systems $[5,6]$. It belongs to permanent magnet motors, just like the permanent magnet brushless DC motor. However, different waveforms of the counter electromotive force, the former counter electromotive force is a sine wave. The advantages of permanent magnet synchronous motors are: wide speed range, high power density, high efficiency, and high-power factor. However, the permanent magnet synchronous motor needs to install permanent magnets on the rotor. Therefore, the cost is relatively high. Improper use can easily cause permanent magnets to demagnetize and demagnetize. At the same time, the rotor structure is not as strong and durable as induction motors and reluctance motors. The operating speed of the motor of the flywheel energy storage system is often in the order of tens of thousands of rpm and is mostly supported by magnetic suspension bearings, which requires relatively high specific power and specific energy. The use of permanent magnet synchronous motors has higher power density and efficiency than permanent magnet brushless DC motors. Greater rotor stiffness is beneficial to increase the maximum speed of the flywheel [7].

The commonly used control strategies for permanent magnet synchronous motors include direct torque control [8] and vector control [9]. Direct torque control is the independent control of motor stator flux and motor torque in the stator stationary coordinate system. By integrating stator voltages, stator flux linkage can be estimated, and then, torque is estimated as a cross product of estimated stator flux linkage and measured motor current vector. By comparing the estimation with reference value, the controller can regulate the torque swiftly. The vector control technology transforms the three-phase AC current, expressed in the stator three-phase static coordinate system, into two DC components in the rotor synchronous rotational coordinate system using coordinate transformation. The two components are the excitation current component and the torque current component, respectively, which can be regulated separately, so that the flux linkage and torque control of the synchronous motor can be decoupled. By changing their combination, the required electromagnetic torque can be achieved [10]. Direct torque control has the advantage of fast dynamic response, but there is a large pulsation. Vector control technology is more mature and stable, and dynamic performance is better, and it is more widely used. Vector control is often used in flywheel energy storage systems driven by permanent magnet synchronous motors.

In order to realize the continuous and stable operation of the flywheel energy storage system, low motor loss, high electromechanical conversion efficiency, high reliability and long life are required. This is also the general principle of this type of motor design [11]. 
Compared with ordinary motors, permanent magnet synchronous motors have smaller size, higher power density, higher switching frequencies and larger losses per unit volume. In addition, the rotor has poor heat dissipation conditions (usually in a vacuum chamber), and excessively high temperature will cause the performance of the motor to decrease and even cause the rotor to demagnetize, which limits the application of flywheel energy storage technology.

The loss of a high-speed permanent magnet synchronous motor includes stator winding loss, core loss, rotor eddy current loss and mechanical loss. Among them, due to the skin effect and proximity effect, the stator winding copper loss and core loss increase with the operating frequency, which account for the main sources of motor loss. Loss analysis and performance optimization under high-frequency conditions have always been key issues in the study of high-speed and high-power motors. The design of heat dissipation system, the improvement of reliability and the expansion of application fields are of great significance to the improvement of a high-speed permanent magnet synchronous motor structure and variable frequency drive scheme. Tao D. et al. [12] analyzed the electromagnetic characteristics of a two-pole $120 \mathrm{~kW}$ high-speed permanent magnet synchronous motor and the core loss characteristics of the stator and pointed out that the core loss in the stator yoke thickness accounted for the main part of the stator core loss; Zhang F. et al. [13] carried out electromagnetic design and loss calculation on a 1.12 MW high-speed permanent magnet motor. The iron loss, winding loss, eddy current loss and friction loss are calculated, considering factors such as the number of poles, the number of stator slots, the diameter of the rotor, the air gap, and the material. Li Y. et al. [14] convert the design of high-speed permanent magnet motors into a multi-objective optimization problem and comprehensively considers various losses in the design process. Du G. et al. [15] and Zhang Y. et al. [16] conducted thermal simulation and experimental analysis of the quasi-MW and MW-class motors studied and gave their respective cooling solutions based on the detailed calculation of the loss characteristics of the high-speed permanent magnet synchronous motor.

In this paper, for the application of a flywheel energy storage system, low-loss design and optimization of high-speed motor under multiple constraints are carried out to reduce the steady-state power consumption of the motor and improve the energy conversion efficiency. The contents of this article are listed as follows: Chapter 2 gives a design and technical specifications of a $300 \mathrm{~kW}$ high-speed motor used in FESS and carries out electromagnetic design and finite element analysis of this design. Chapter 3 analyzes the operating characteristics of this high-speed motor design. Chapter 4 gives a detailed loss analysis of how the high-speed motor is used in FESS, including the high-frequency winding loss resulting from the skin effect and proximity effect; the high-frequency core loss includes eddy current loss and hysteresis loss, the rotor eddy current loss and other losses. Chapter 5 is the conclusion.

\section{Integrated Motor Design}

\subsection{High-Speed Motor Solutions and Technical Specifications}

The research object of this paper is the permanent magnet synchronous motor/generator (PMSG) used in the magnetic levitation flywheel energy storage system (FESS), which mainly aims at high efficiency, high speed and high output. The rated speed of the motor is $30 \mathrm{krpm}$. The rated power in power generation mode is $300 \mathrm{~kW}$. The motor/generator structure of the flywheel energy storage system is shown in Figure 1. The stator has a general AC motor stator shape. The rotor is made of a cylindrical permanent magnet wrapped with a metal sleeve and supported by radial and axial magnetic bearings. The rotor of the flywheel energy storage system operates in a near vacuum environment. The heat inside the shell is naturally transferred to the surface of the shell through the air between the shell and the rotor. Therefore, determining the amount of heat generated by the motor is crucial for choosing the cooling method of the flywheel energy storage system. When the flywheel energy storage system starts to operate, the flywheel energy storage system is driven by 
the inverter, and the flywheel speeds up to $30 \mathrm{krpm}$. At such a speed, even in the absence of input power, core loss will still occur in the stator due to the high-speed rotation of the permanent magnet rotor. In order to reduce the loss of the stator, the material of the stator core should be selected reasonably and the geometry of the motor should be optimized. For the design of permanent magnet synchronous motors, several feedback processes between electromagnetic design and structural design should be used to determine whether the design data can meet the requirements. What has been listed hereinafter is the technical parameters of the flywheel energy storage system. In generator design, the most important thing is to meet the requirements of efficiency and output power at $30 \mathrm{krpm}$, and the design should be carried out within a given space size range. Table 1 listed the motor's technical specifications with its stator dimensions.

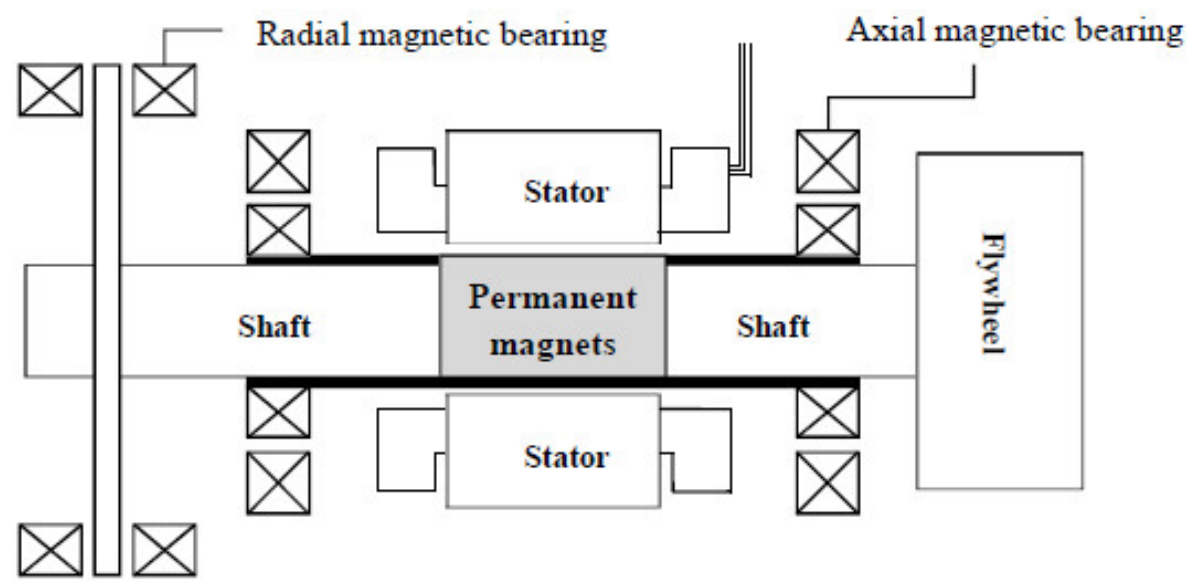

Figure 1. Schematic diagram of flywheel energy storage system.

Table 1. Motor technical specifications.

\begin{tabular}{cc}
\hline Description & Value \\
\hline (Generation mode) output power & $300 \mathrm{~kW}$ \\
(Electric driven mode) input power & $30 \sim 60 \mathrm{~kW}$ \\
DC bus voltage & $540 \mathrm{Vdc}$ \\
Synchronous speed & $30,000 \mathrm{rpm}$ \\
Efficiency at 30,000 rpm & $98 \%$ \\
Outer diameter of stator & $250 \mathrm{~mm}$ \\
Stator inner diameter & $146 \mathrm{~mm}$ \\
Stator core length & $180 \mathrm{~mm}$ \\
Cooling method & Stator natural air cooling \\
\hline
\end{tabular}

Figure 2 shows the electric driven mode and power generation mode of FESS. In the electric driven mode, the $\mathrm{AC}$ power source $\mathrm{AC}$ is converted to $\mathrm{DC}$ by an $\mathrm{AC} / \mathrm{DC}$ converter. The flywheel is rotated through the DC/AC inverter to the target speed of $30 \mathrm{krpm}$. After that, only the minimum power to maintain the speed is continuously provided, and the shaft that reaches $30 \mathrm{krpm}$ can overcome the rotation resistance to maintain this speed. In the power generation mode, it operates in the opposite way and feeds the generated electrical energy back to the grid. In an emergency, a shaft rotating at $30 \mathrm{krpm}$ transmits the generated energy to the grid. In the process of energy transfer, a reaction torque will be generated on the shaft, causing the speed to decrease rapidly. During the period when the rotating shaft speed is reduced from 30 to $15 \mathrm{krpm}$ within $15 \mathrm{~s}$, it is necessary to be able to output $300 \mathrm{~kW}$ of power. When the rotating shaft speed is $15 \mathrm{krpm}$, the voltage generated will drop by $50 \%$, so the output current will be twice the original. The reduced voltage will be increased by a voltage boost device. 


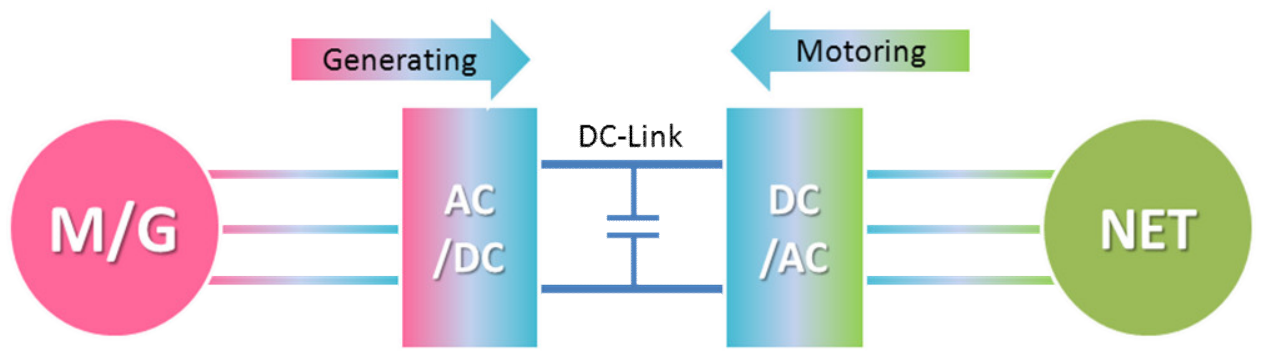

Figure 2. Electric/power generation system.

\subsection{Electromagnetic Design}

The rated power of the motor studied in this paper is $300 \mathrm{kw}$. Considering the requirements of motor weight, no-load loss and back electromotive force, the number of poles and slots and the winding method of the motor should be reasonably selected. The number of poles of high-speed motors is generally small and its combination with the slot structure design greatly affects the overall performance of the motor $[17,18]$. The available option is either two poles or four poles, and each has its advantages and disadvantages. The advantage of a two-pole motor is that the permanent magnets of the rotor can be integrated into a compact structure. It ensures that the rotor's mechanical structure is isotropic in the radial direction, which is beneficial to the dynamic balance of the rotor. At the same time, it can reduce the alternating frequency of the stator winding current and the magnetic field in the iron core, which lead to reduced high-frequency additional loss. The disadvantage of a two-pole motor is that the stator winding ends are longer and the core yoke is thicker. On the contrary, the advantage of a four-pole motor is that the stator winding ends are shorter and the core yoke is thinner; while the disadvantage is that the permanent magnet rotor requires multiple permanent magnets to be spliced, which reduces the rigidity of the rotor. At the same time, the alternating frequency of the stator winding current and the magnetic field in the iron core is higher, which increases the iron loss. From the perspective of electromagnetic and mechanical considerations, especially the mechanical strength and rigidity of the rotor, it is more advantageous to adopt the two-pole solution. After the number of poles is determined, the number of corresponding slots is easier to determine. Usually a stator with a 24-slot structure is used, and the winding method is a double-layer distributed winding. The appropriate pitch is selected to improve the electromotive force and magnetomotive force waveform.

The main size of the PMSM can be determined by the required electromagnetic power requirements and the preselected electromagnetic load value. The size is given by the following equation [19]:

$$
P=\frac{\pi}{60} \alpha_{i} K_{B} K_{d p} D_{i 1}^{2} L_{1} n A_{1} B_{\delta}
$$

where $P$ is the electromagnetic power; $\alpha_{i}$ is the calculated pole arc coefficient; $K_{B}$ is the air gap magnetic field waveform coefficient; $K_{d p}$ is the winding coefficient; $D_{i 1}$ is the stator inner diameter; $L_{1}$ is the iron core length; $n$ is the motor speed; $A_{1}$ is the electric load; $B_{\delta}$ is the air gap magnetic density.

According to the requirements of the motor layout and the space limitation of the flywheel cavity, the effective length of the stator is initially selected to be $150 \mathrm{~mm}$, and the electrical load generally ranges from 150 to $500 \mathrm{~A} / \mathrm{mm}$. According to the heat dissipation condition of the motor, which is natural cooling, the load is set as $377 \mathrm{~A} / \mathrm{mm}$, while the magnetic load of the motor is $0.8 \mathrm{~T}, K_{B}$ and $K_{d p}$ are, respectively, 1.1 and 0.96 . The length of the motor air gap has a great influence on the performance of the motor. Properly increasing the air gap length can reduce torque ripple and harmonic components and can also reduce the eddy current loss in the permanent magnet and reduce the risk of permanent magnet demagnetization. From the perspective of installation, appropriately increasing the air gap can facilitate the installation of the flywheel rotor. However, increasing the air gap can also cause the raise of reluctance and consequently the decrease in power factor. 
In the stator shape design, the following content needs to be considered: (a) design the magnetic circuit to make the magnetic flux energy conversion smooth; (b) design the winding to generate the required three-phase voltage; (c) determine the slot shape to locate the winding. At this time, the following items should be estimated:

(a) Conductors of each phase: estimate the number of serials turns based on the driven voltage and the generation voltage;

(b) Number of slots: estimate the number of slots in the stator by determining the number of slots for each pole;

(c) Slot area: estimate the required slot section based on the current density.

Under open circuit conditions, through equivalent circuit analysis or finite element analysis, it is necessary to modify the shape of the stator many times. In open circuit analysis, a magnetic flux path must be established so that magnetic flux saturation does not occur. The magnet material plays a vital role in the allowed magnetic flux. The rotor studied here uses samarium-cobalt (SmCo) magnets, which is a strong rare-earth permanent magnet made of samarium and cobalt alloy. SmCo magnets generally have a higher temperature rating and higher coercivity, and they are the only viable material with an operating temperature above $250{ }^{\circ} \mathrm{C}$ [20]. In particular, the maximum energy range of the $\mathrm{Sm}_{2} \mathrm{Co}_{17}$ products of these alloys is $20 \sim 32 \mathrm{MGOe}$, which is about $160 \sim 260 \mathrm{~kJ} / \mathrm{m}^{3}$. These alloys have the best reversible temperature coefficient of all rare earth alloys, usually $-0.03 \% /{ }^{\circ} \mathrm{C}$. However, they are very brittle and can easily crack and chip. Table 2 lists the typical range of properties of Sm2Co17 materials.

Table 2. Typical range of Sm2Co17 (2:17 alloy) properties.

\begin{tabular}{|c|c|c|c|c|c|c|c|c|}
\hline \multirow[b]{2}{*}{ Material } & \multicolumn{2}{|c|}{$B r$} & \multicolumn{2}{|c|}{$H c(H c b)$} & \multicolumn{2}{|c|}{ Hci (Hcj) } & \multicolumn{2}{|c|}{ BHmax } \\
\hline & $\mathbf{T}$ & kG & $\mathrm{kA} / \mathrm{m}$ & kOe & $\mathrm{kA} / \mathrm{m}$ & kOe & $\mathrm{kJ} / \mathrm{m}^{3}$ & MGOe \\
\hline $\mathrm{SmCo} 24 \mathrm{H}$ & $0.95-1.02$ & $9.5-10.2$ & $700-750$ & $8.7-9.4$ & $>1990$ & $>25$ & 175-191 & $22-24$ \\
\hline $\mathrm{SmCo} 26 \mathrm{H}$ & $1.02-1.05$ & $10.2-10.5$ & $750-780$ & $9.4-9.8$ & $>1990$ & $>25$ & 191-207 & $24-26$ \\
\hline $\mathrm{SmCo} 28 \mathrm{H}$ & $1.03-1.08$ & $10.3-10.8$ & $756-796$ & 9.5-10.0 & $>1990$ & $>25$ & $207-220$ & $26-28$ \\
\hline $\mathrm{SmCo} 30 \mathrm{H}$ & $1.08-1.10$ & $10.8-11.0$ & 788-835 & 9.9-10.5 & $>1990$ & $>25$ & $220-240$ & $28-30$ \\
\hline
\end{tabular}

In Figure 3, the magnetic flux shown by the designed stator is consistent with the designed magnetic flux. Figure $3 a$ is the magnetic line of force distribution in the stator when there is no load. Figure $3 b$ shows the magnetic flux density distribution of the stator cross-section. The local magnetic flux density saturation does not exceed 1.6 T. Figure 4 is a graph of the magnetic flux distribution along the semicircular curve of the contour of the yoke and slot teeth in the stator. It can be determined that the magnetic flux density does not exceed $1.6 \mathrm{~T}$.

Using a two-pole, 24-slot motor structure, the three-phase winding arrangement under Y-connection is shown in Figure 5. Figure 6 is the axial and radial cross-sectional view of the permanent magnet synchronous motor, including the stator core, stator laminated fixed layer, end coils, sheath and permanent magnets (Sm2Co17-26H). The length, outer diameter of the stator, outer diameter of the permanent magnet and thickness of the sheath are all determined according to the characteristics and rigidity of the rotating structure. This is the starting point for determining the volume in the design. The thickness of the sheath and length of the shaft are the most important factors in the structural design.

The rotating shaft with permanent magnets generates electromotive force at the stator coil terminals according to the rotation speed. The electromotive force increases with the increase in length, speed and magnetic flux density, as shown in Equation (2).

$$
e_{p h}=k_{w} N_{p h} e_{c}=k_{w} N_{p h}\left(N_{c} B \omega_{m} D L\right)
$$

Combining the finite element model and the simulation calculation of the circuit to calculate the electromotive force (EMF), the circuit is shown in Figure 7. 


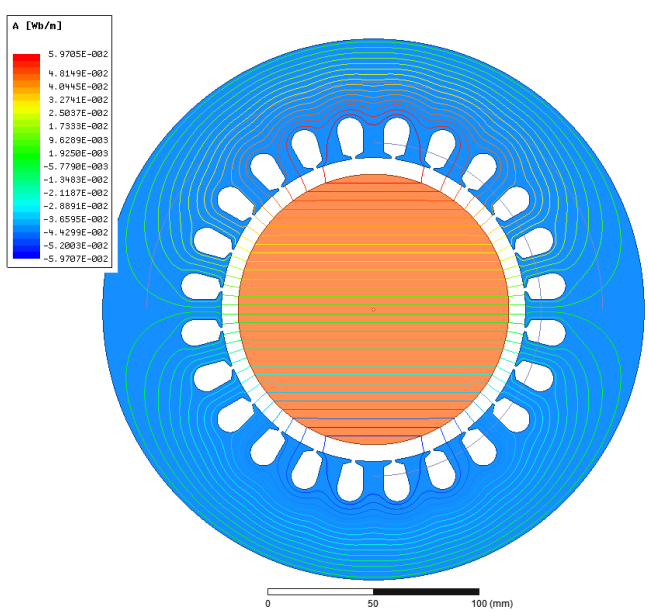

(a)

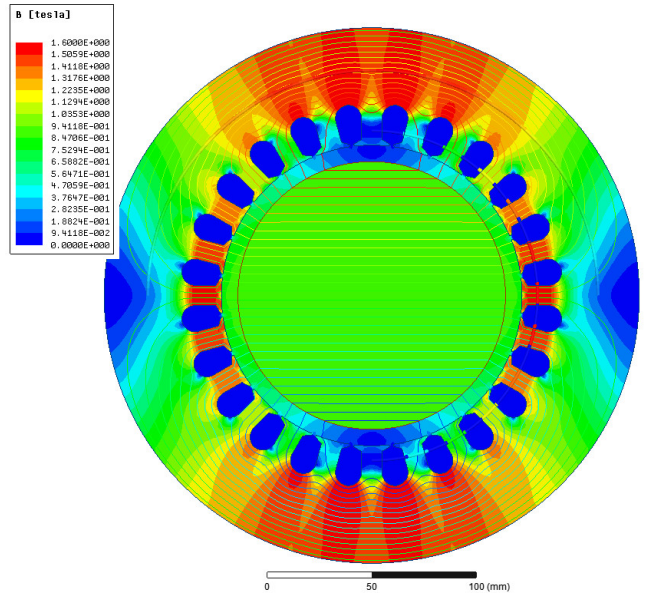

(b)

Figure 3. Stator magnetic flux distribution under no load: (a) The magnetic flux line distribution. (b) The magnetic flux density distribution.

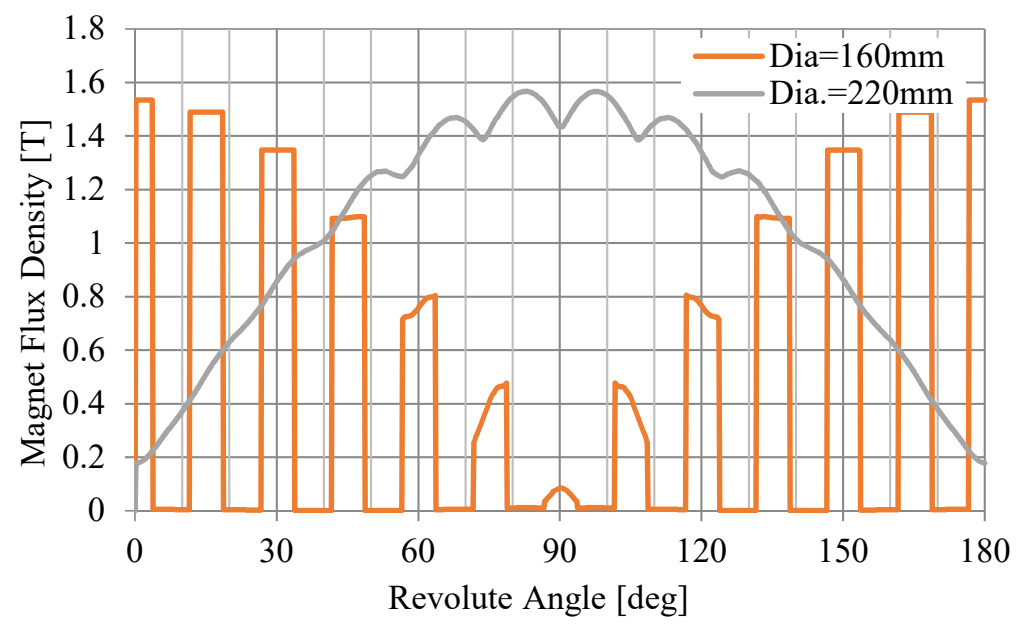

Figure 4. The magnetic flux density on the inner contour of the stator under no load.

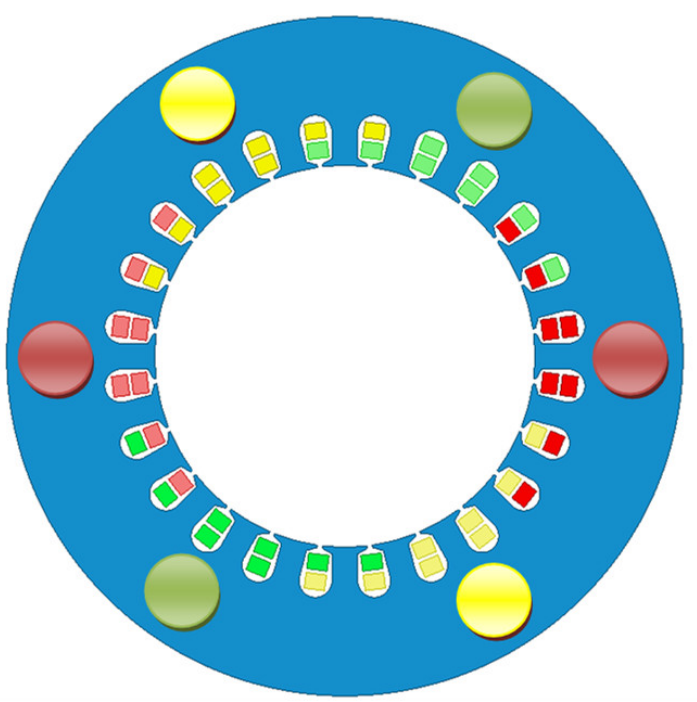

Figure 5. Three-phase winding distribution. 

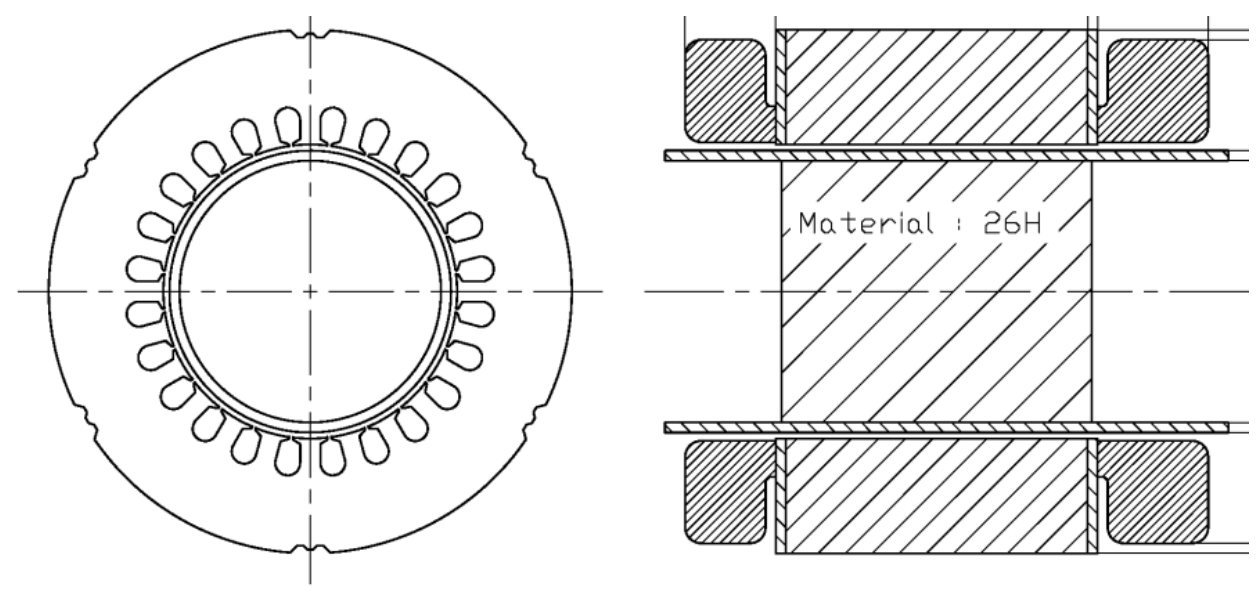

Figure 6. Cross-section of permanent magnet synchronous motor.

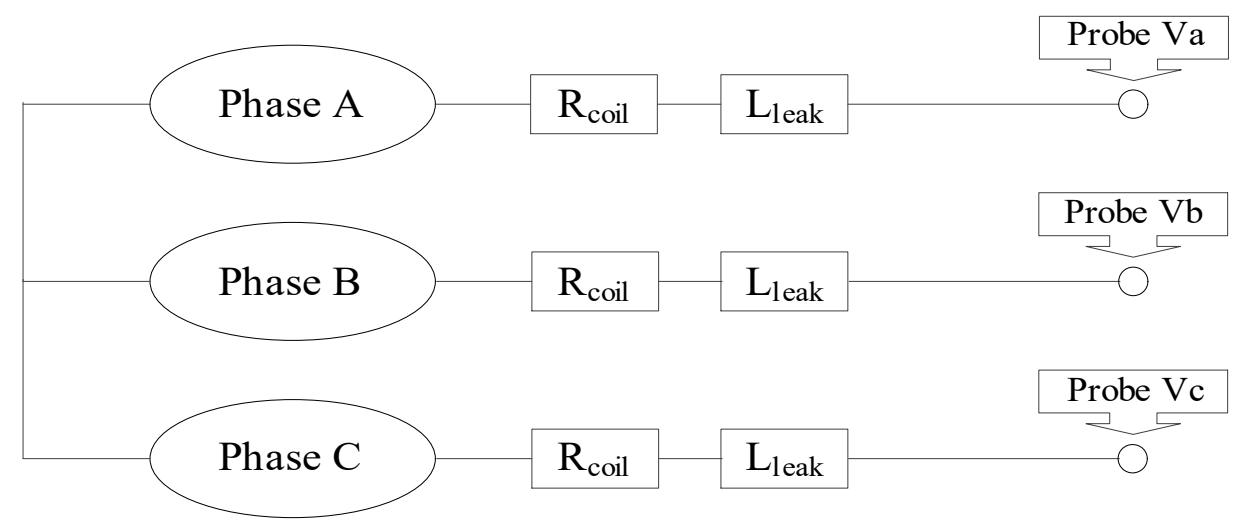

Figure 7. Back-EMF simulation circuit.

In Figure 8, the back-EMF diagrams are obtained through simulation calculations at 15 and $30 \mathrm{krpm}$, respectively. Figure 9 is a graph of the electromotive force as the speed increases, and the back electromotive force coefficient is $0.012[\mathrm{~V} / \mathrm{rpm}]$.

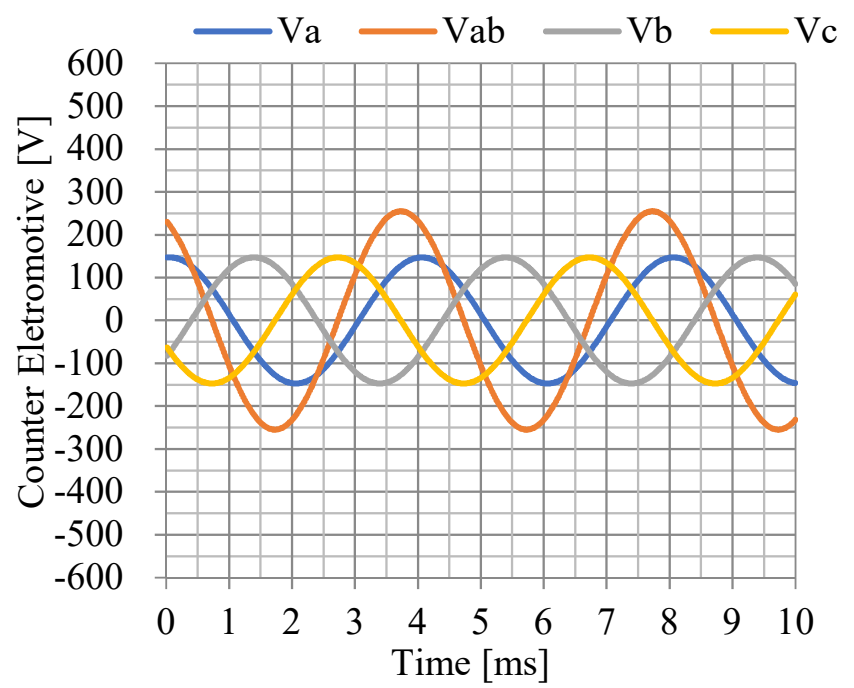

(a)

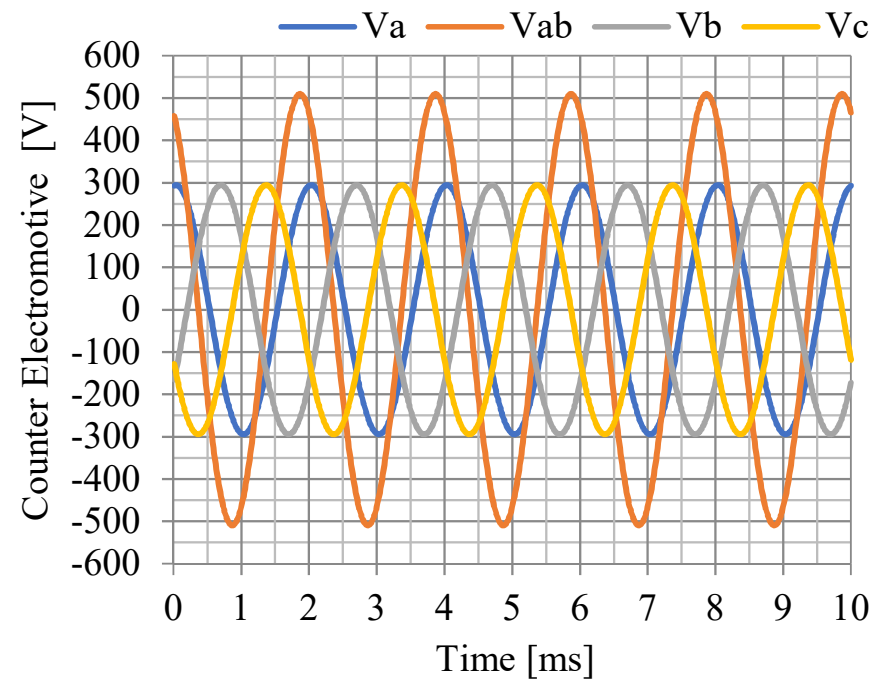

(b)

Figure 8. Back-EMF when open circuit. (a) $15 \mathrm{krpm}$. (b) $30 \mathrm{krpm}$. 


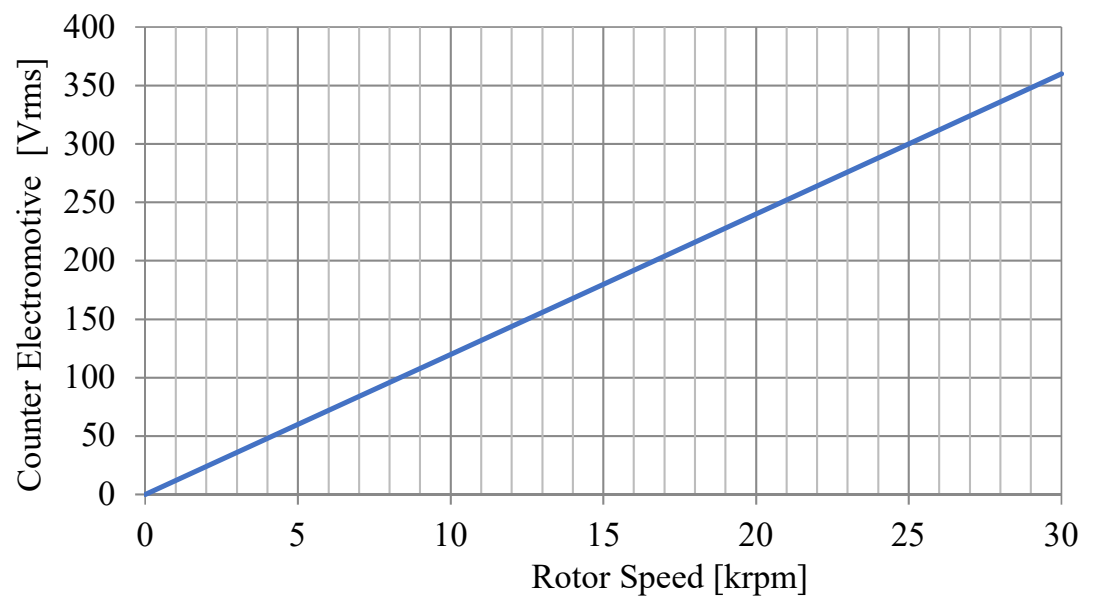

Figure 9. The change in Back-EMF versus rotor speed.

\section{Analysis of Operating Characteristics of High-Speed Motors}

\subsection{Electric Driven Mode}

At startup, FESS accelerates to $30 \mathrm{krpm}$ in the electric driven mode. The applied power is determined by the acceleration time and the moment of inertia in the simulation process, assuming that the input power is 30 and $60 \mathrm{~kW}$, respectively. At a constant speed, the iron loss changes, whereas the power stays basically unchanged. Table 3 list the operational characteristics of the motor at $30 \mathrm{krpm}$ electric driven mode. Figures 10 and 11 depict the input voltage, input current, input power and loss characteristics of the motor at $30 \mathrm{krpm}$ with an input power of 30 and $60 \mathrm{~kW}$, respectively.

Table 3. Characteristics of $30 \mathrm{krpm}$ electric driven mode.

\begin{tabular}{ccccc}
\hline Power $[\mathbf{k W}]$ & Speed $[\mathrm{krpm}]$ & Voltage $[\mathrm{V}]$ & Current $[\mathrm{A}]$ & Core loss $[\mathrm{kW}]$ \\
\hline 30 & 30 & 364 & 56 & 1.6 \\
60 & 30 & 370 & 100 & 1.6 \\
\hline
\end{tabular}

\subsection{Rated Load (Generation Mode)}

The power control system (PCS) is added to the actual power generation system, but the load library is assumed in the finite element analysis for simulation. Figure 12 shows the coupling circuit diagram used in simulation. When the FESS rotates at $30 \mathrm{krpm}$, the output is changed by adjusting the $R_{\text {load }}$ value, so that the output power is $300 \mathrm{~kW}$ when the load circuit is turned on. When decelerating to $15 \mathrm{krpm}, R_{\text {load }}$ should be changed to output $300 \mathrm{~kW}$.

When the speed slows down, the generated voltage decreases proportionally. Therefore, in order to obtain a constant output power, the current needs to be increased. The simulation results show this characteristic, as shown in Table 4. Figures 13 and 14 depicts the output voltage, output current, output power and loss characteristics of the motor in $300 \mathrm{~kW}$ power generation mode at 30 and $15 \mathrm{krpm}$, respectively.

Table 4. Characteristics in power generation mode.

\begin{tabular}{ccccc}
\hline Power [kW] & Speed [krpm] & Voltage [V] & Current [A] & Core Loss [kW] \\
\hline 300 & 30 & 360 & 495 & 1.6 \\
300 & 15 & 178 & 993 & 0.6 \\
\hline
\end{tabular}




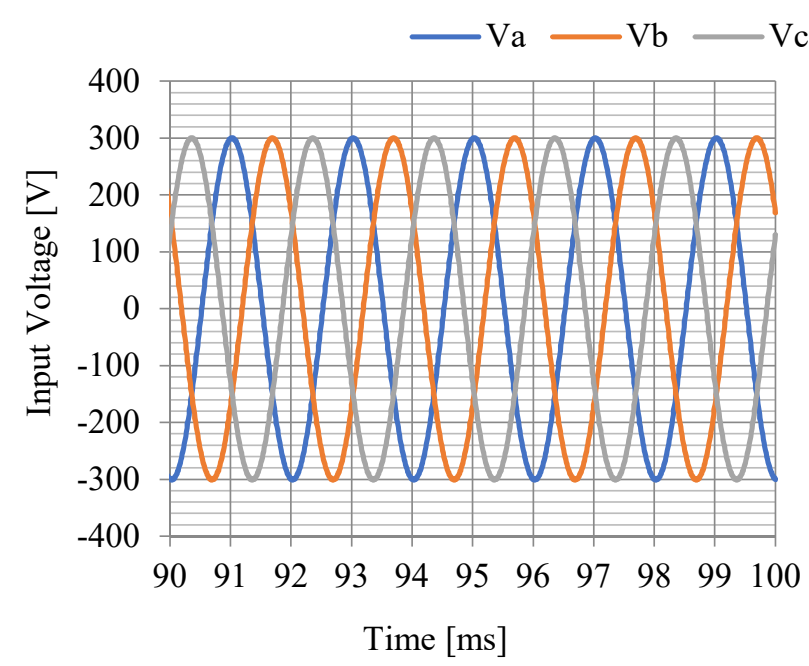

(a)

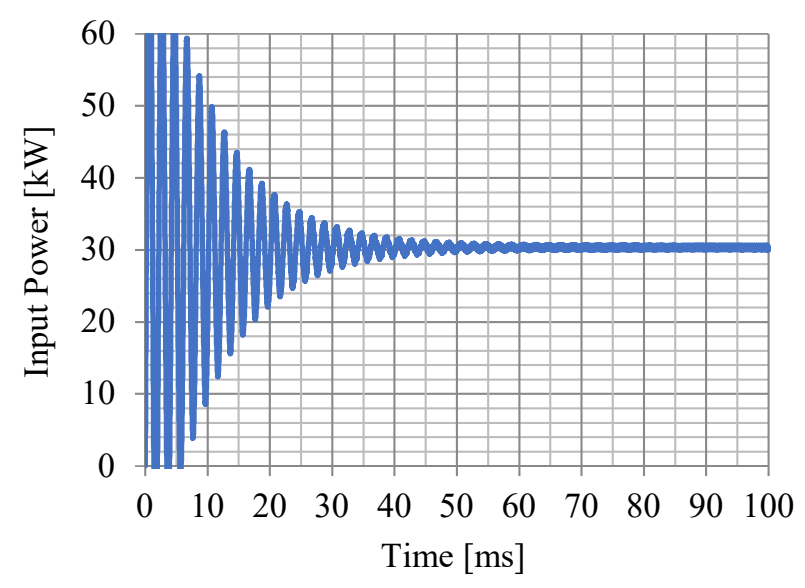

(c)

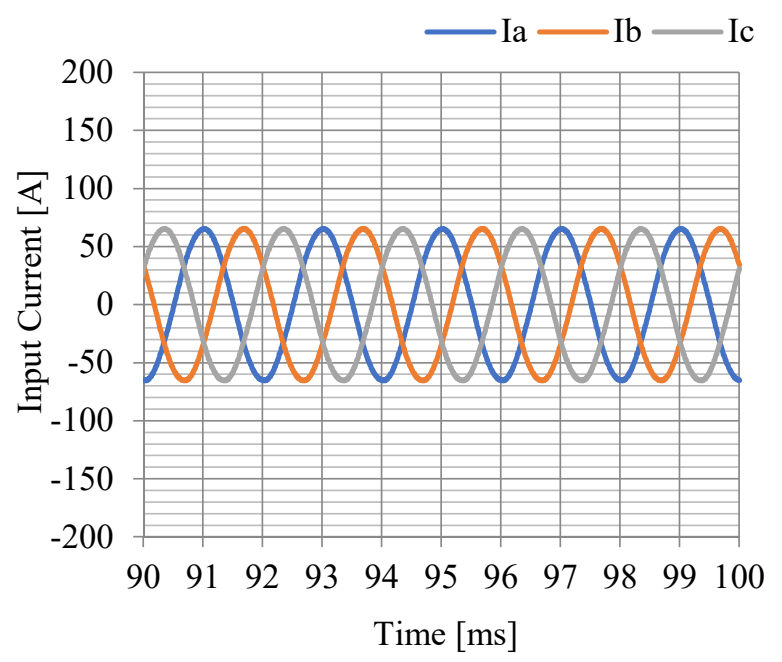

(b)

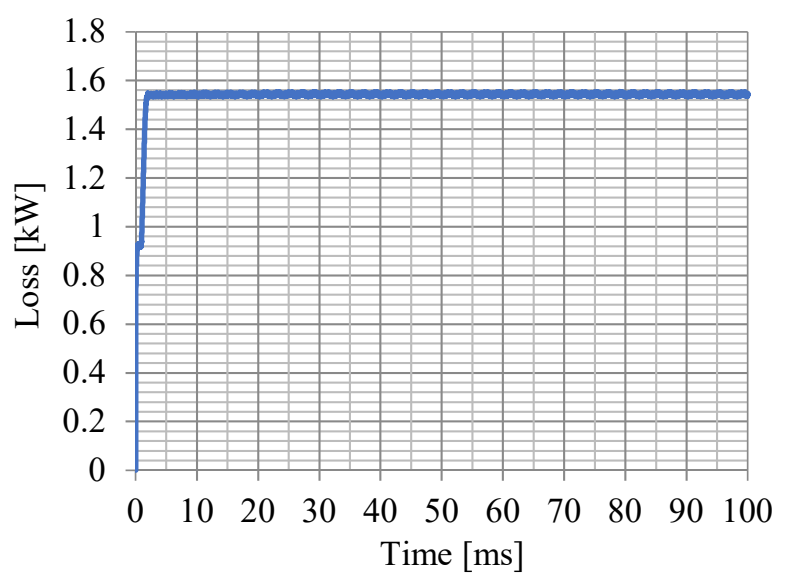

(d)

Figure 10. Characteristics at $30 \mathrm{krpm}$ (30 kW electric driven mode): (a) Input voltage. (b) Input current. (c) Input power. (d) Loss.

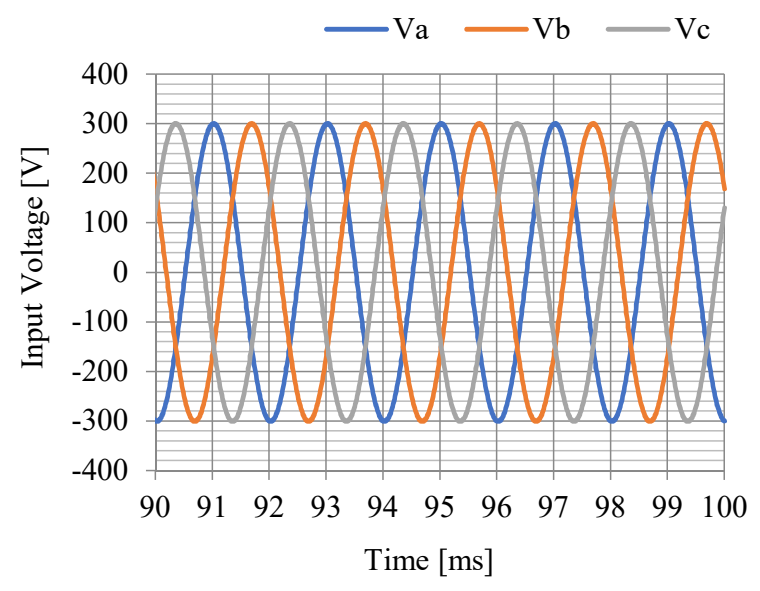

(a)

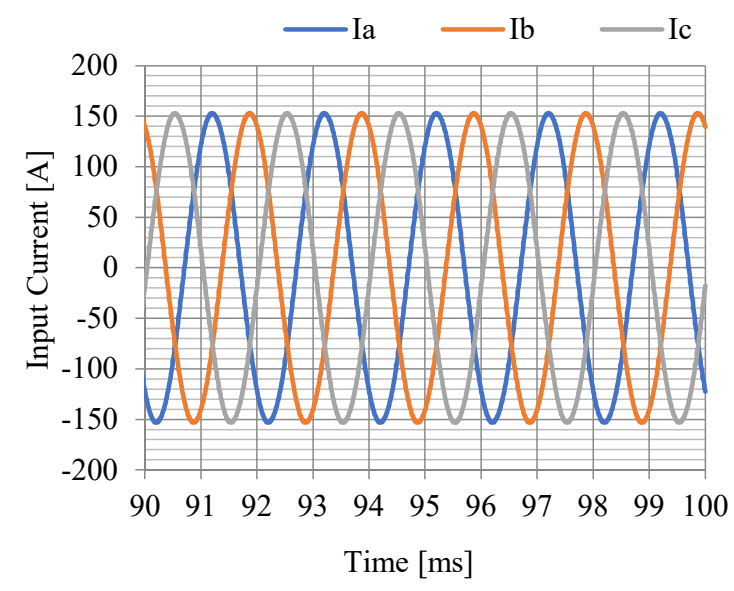

(b)

Figure 11. Cont. 


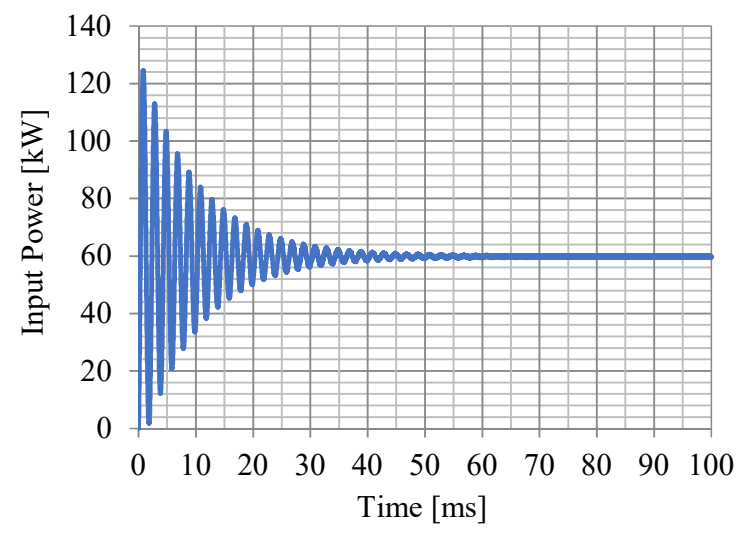

(c)

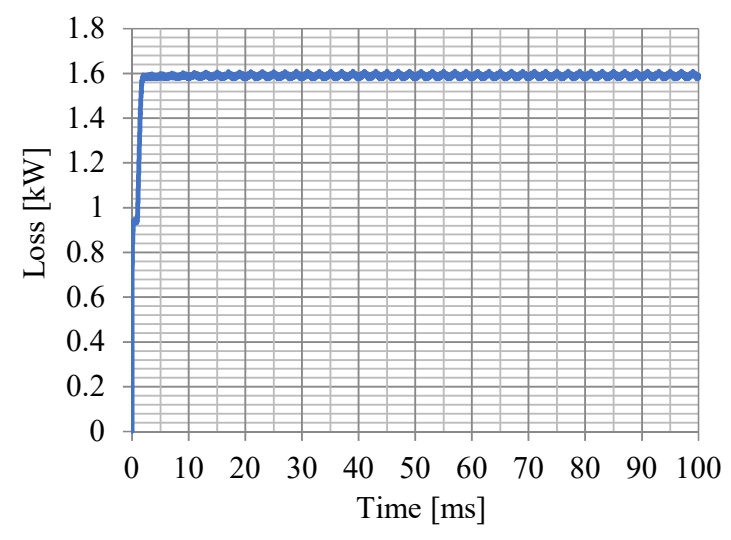

(d)

Figure 11. Characteristics at $30 \mathrm{krpm}(60 \mathrm{~kW}$ electric driven mode): (a) Input voltage. (b) Input current. (c) Input power. (d) Loss.

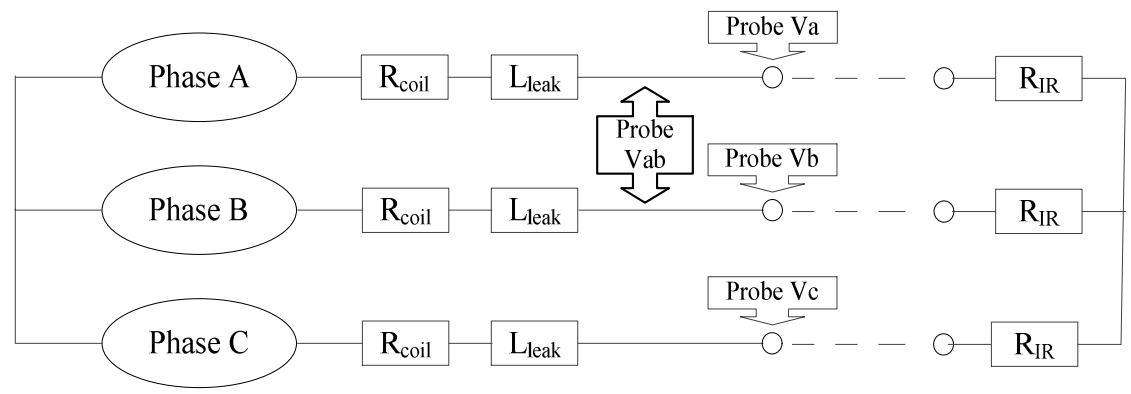

Figure 12. Coupling circuit diagram.

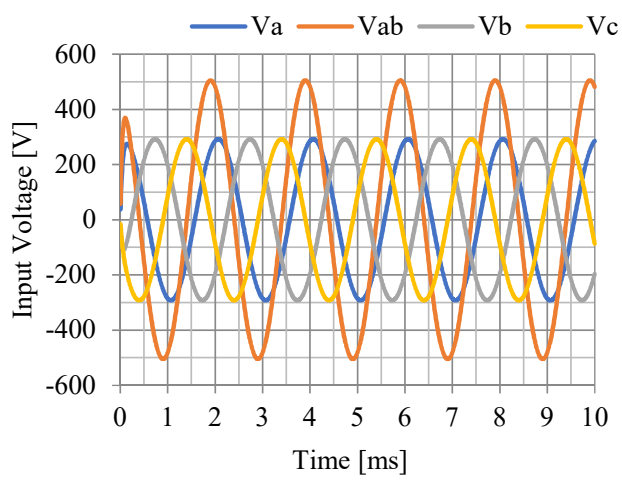

(a)

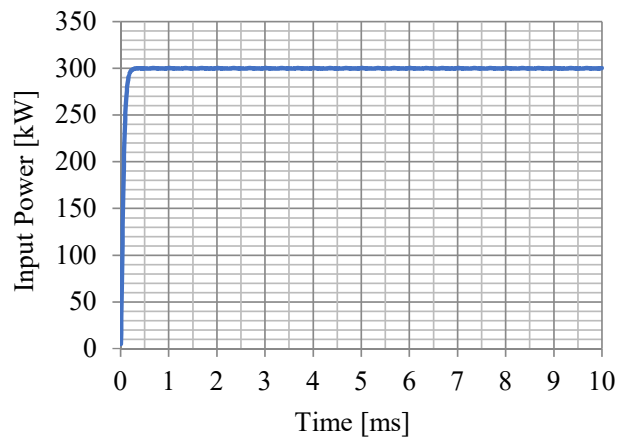

(c)

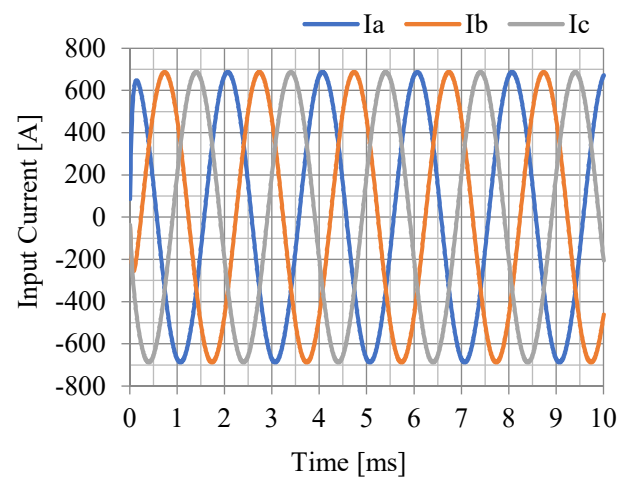

(b)

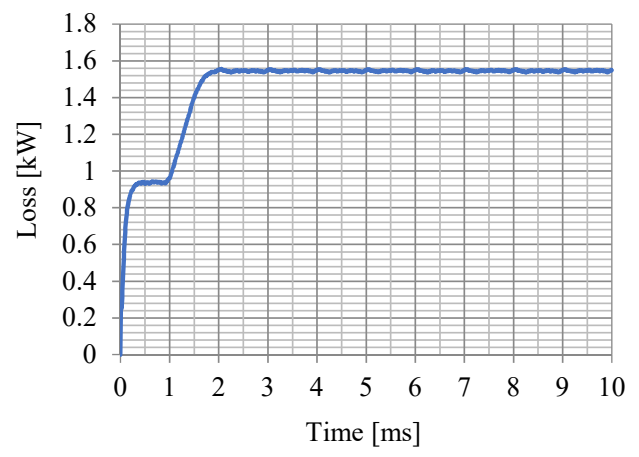

(d)

Figure 13. Characteristics at $30 \mathrm{krpm}(300 \mathrm{~kW}$ power generation state): (a) Output voltage. (b) Output current. (c) Output power. (d) Loss. 


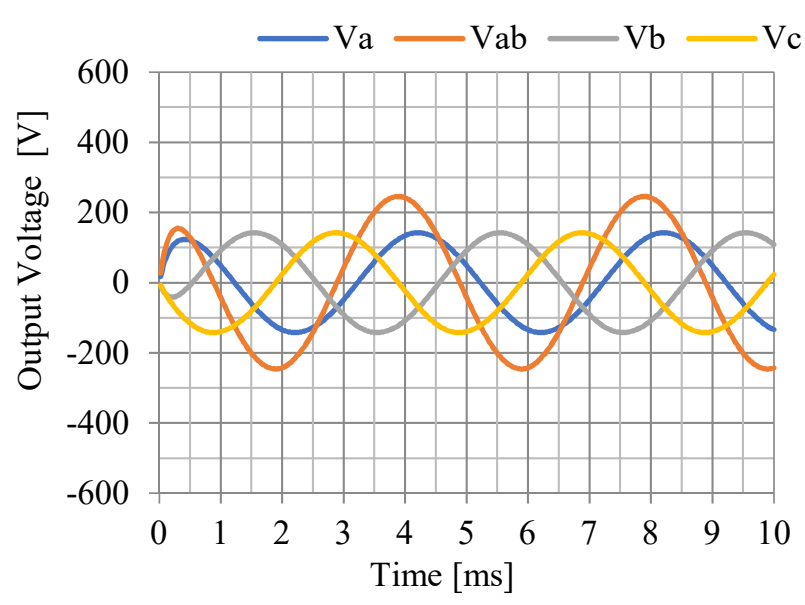

(a)

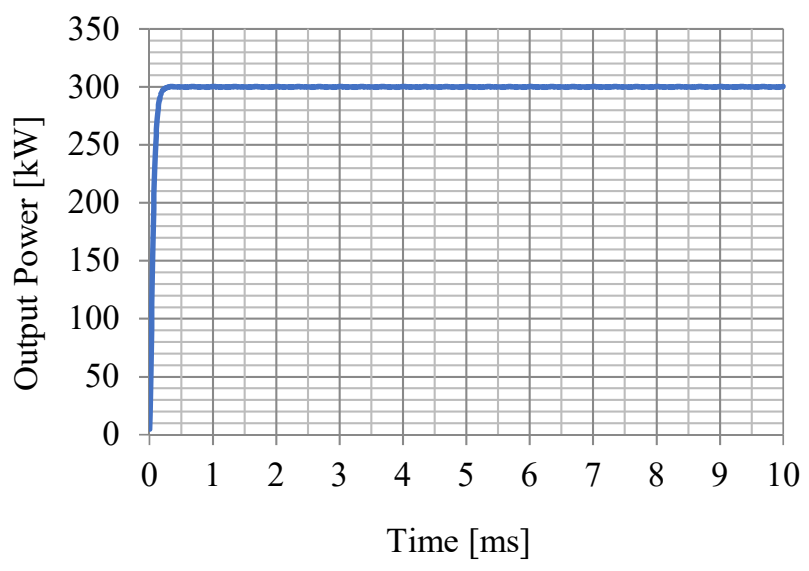

(c)

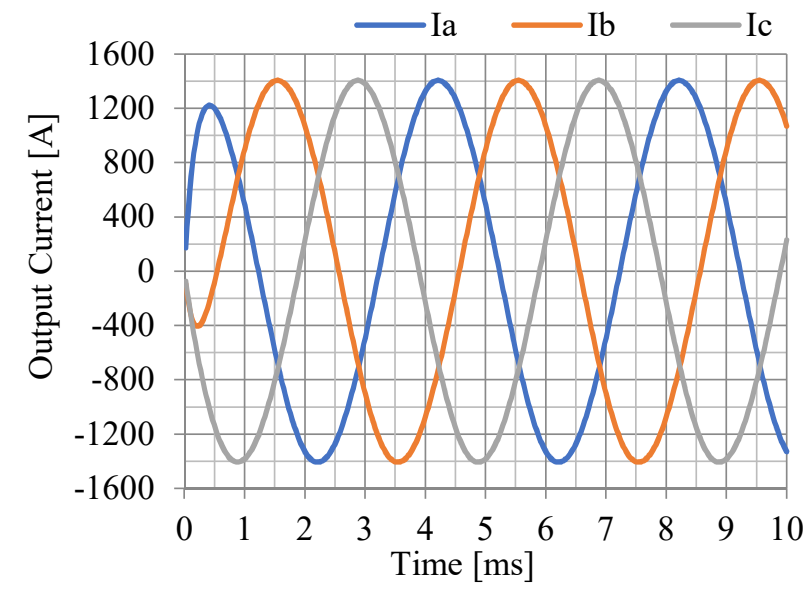

(b)

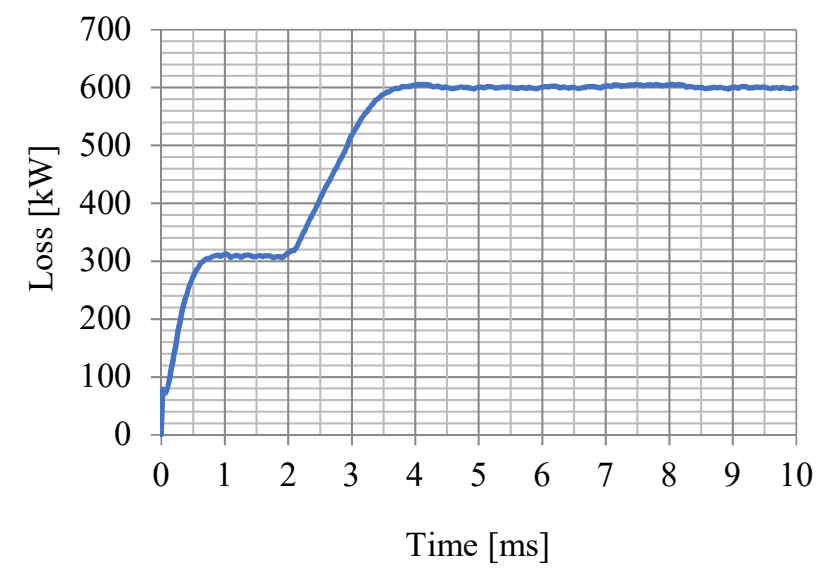

(d)

Figure 14. Characteristics at $15 \mathrm{krpm}$ (300 kW power generation state): (a) Output voltage. (b) Output current. (c) Output power. (d) Loss.

\section{Loss Analysis}

\subsection{Composition of High-Speed Motor Loss}

Motor loss includes winding loss, core loss, rotor eddy current loss and mechanical loss. Since the motor in this article uses a magnetic suspension bearing to support the rotor, there is almost no mechanical friction loss. On the electric side, the high-frequency current of high-speed motors will cause the skin effect, proximity effect and high-order harmonics to become obvious, resulting in increased motor losses. At the same time, the changes in the proportion of different types of losses are also obvious. Due to the high speed of the high-speed motor and the high frequency of the winding current, the iron loss and copper loss per unit volume of the stator, the high-frequency eddy current loss of the rotor and the surface air friction loss are much larger than those of ordinary motors of the same power level.

During the operation of high-speed motors, the above-mentioned losses can generally be divided into the following categories:

(1) Stator loss, which is divided into iron loss and copper loss. Stator iron loss refers to the loss caused by the change in the main magnetic field in the iron core. Whether it is alternating magnetization or rotating magnetization, it will cause hysteresis loss and eddy current loss in the core. The stator copper loss is composed of basic copper loss and additional copper loss. Basic copper loss refers to the loss caused by the working current in the copper winding. Additional copper loss refers to the high-frequency additional loss in the winding due to the skin effect of the alternating magnetic field. 
The high-frequency additional loss of the winding is related to many factors such as the working frequency of the motor, the size of the winding conductor and the arrangement position in the slot.

(2) Rotor loss, which is divided into air friction loss on the rotor surface and rotor eddy current loss. The air friction loss on the rotor surface refers to the loss caused by the friction between the rotor and the surrounding air when the rotor is running at high speed. It is related to the speed, air flow rate and the roughness of the rotor surface. The eddy current loss of the rotor refers to the eddy current loss generated in the rotor sheath and permanent magnet by the space and time harmonics of the air gap magnetic field.

Among the above losses, the basic copper loss of the stator winding can be obtained by the winding current value and the resistance value. Although it is difficult to obtain the high-frequency additional copper loss of the winding accurately through analytical methods, the high-speed electrical circuit coupled transient finite element analysis can obtain a more accurate calculation result of the high-frequency loss of the stator winding. To calculate stator iron loss, the current more classic calculation method is to establish a discrete Bertotti's iron loss model, which means the iron loss is divided into three parts, namely hysteresis loss, classic eddy current loss and abnormal eddy current loss [21]. The accuracy of iron loss calculation depends on two conditions. One is that the loss coefficient of the iron core material should be selected correctly; the other is that the magnetic flux density of each part of the iron core should be calculated correctly. For high-speed motors, due to the relatively high speed of the rotor, the air friction loss on the surface of the rotor is much greater than that of ordinary motors. At the same time, in order to avoid high-frequency electromagnetic waves from causing hysteresis loss and eddy current loss in the permanent magnet, a metal shielding sleeve is usually installed on the surface of the permanent magnet. However, how to calculate the eddy current loss in the sheath still needs to establish a model for analysis.

\subsection{High-Frequency Winding Loss}

The skin effect and proximity effect caused by the alternating current will increase the copper loss of the motor winding, especially for a high-speed motor with a relatively high fundamental frequency of the current. The additional copper loss caused by the skin effect and proximity effect will greatly increase. In the stator slots of a high-speed permanent magnet synchronous motor, in addition to the fundamental wave leakage flux, there is also the leakage flux generated by the stator slot and the inverter PWM modulation current harmonics. The frequency of these leakage fluxes is relatively high, which will cause large AC losses in the stator windings. The AC loss of the motor winding is not only related to the diameter of the conductor, but also related to many factors such as the slot size, the location of the conductor and the frequency of the current harmonics.

The AC loss of the winding is closely related to the diameter of the conductor. When the frequency and amplitude of the current is constant, the AC loss of the winding has a minimum value as the diameter of the conductor varies. The higher the frequency, the larger the minimum value can achieve, where conductor diameter can also achieve an optimal minimal value. Meanwhile, the magnetic field at the conductor closest to the slot notch directly affects the magnitude of the AC loss of the winding. As the height of the notch increases and the width of the notch decreases, the AC loss of the winding will increase accordingly, and the influence of the notch width is greater than the influence of the notch height. When the windings are placed in an offset slot, the AC loss is obviously greater than the AC loss in the middle and offset slot bottom placement, but it is closer to the AC loss when the winding is placed evenly. The current harmonics caused by inverter PWM modulation also have a great influence on the AC loss of the winding. As the PWM carrier ratio of the inverter increases, the AC loss of the winding decreases. However, the rate of decrease gradually slows down as the carrier ratio increases. High-speed motors will cause high-frequency additional eddy current copper loss in the windings due to the 
skin effect and proximity effect. This part of the loss is defined as eddy current loss, and DC loss is collectively called AC loss.

In order to suppress the generation of eddy currents, high-speed permanent magnet synchronous motor windings usually use multiple thin copper wires in parallel. As the energization frequency increases, the penetration depth of the copper wire decreases monotonously, the skin effect becomes more pronounced, and the Joule loss increases. In order to reduce the Joule loss of the current flowing outside the wire, the diameter of the copper wire should be less than twice the penetration depth. However, eddy currents caused by a time-varying external magnetic field still exist in the wire at this time, and the ratio of diameter to penetration depth needs to be further reduced. In this paper, 70 wires with a diameter of $0.64 \mathrm{~mm}$ are used in the motor to reduce the eddy current loss and the winding process when winding, and the eddy current loss can be further reduced by placing the wires as close to the bottom of the groove as possible.

The input power while charging the energy storage flywheel motor is $30 \sim 60 \mathrm{~kW}$, and the copper consumption is 30 90 W. The standby current is smaller than the charging current, and the copper consumption of the energy storage flywheel is relatively large during high-power discharge. The output current of the motor at 30,000 and 15,000 r/min and the discharge power of $300 \mathrm{~kW}$ correspond to the copper consumption of 2.1 and $8.6 \mathrm{~kW}$, respectively.

\subsection{High-Frequency Core Loss}

The most classic method to calculate the iron loss of a motor is the ratio loss method. This method scales the iron loss of the stator material under a certain frequency and magnetic density to the working frequency and magnetic density of the motor according to a certain rule and, then, uses empirical coefficients to modify the results. Because of the small amount of data required and the fast calculation speed, it has been widely used in traditional motor design. For general motors, the iron loss can be calculated according to the loss curve and empirical formula of the iron core steel sheet under the excitation of the power frequency sine wave power supply. However, for special motors, especially highspeed permanent magnet motors, the speed is tens of thousands of revolutions per minute, and the power supply frequency can reach thousands of hertz. In such high-frequency, high-speed conditions, if still using the silicon loss curve and the empirical formula of the sinusoidal frequency, iron loss computing power would bring great error. The iron loss error will have a direct impact on the accurate design of high-speed permanent magnet motors, which limits practical applications.

Core loss includes eddy current loss and hysteresis loss. Among them, the eddy current loss is closely related to the thickness of the silicon steel sheet used. The penetration depth of the silicon steel sheet is small at high frequencies. The magnetically dense skin effect and eddy current density skin effect of silicon steel sheet is significant, and the Joule loss is large. In order to suppress the generation of eddy currents, the core of high-speed permanent magnet synchronous motors is usually laminated with multiple thin silicon steel sheets. In addition, when the magnetically permeable material is repeatedly magnetized in an alternating magnetic field, the magnetic induction and magnetic field strength inside the material present a hysteresis loop. At this time, energy loss will be caused in the magnetic material, which is called core loss. Silicon steel sheets in a time-varying magnetic field will produce hysteresis losses. The hysteresis loss of the silicon steel sheet is proportional to the alternating frequency of the magnetic field and the area enclosed by the hysteresis loop. The area of the hysteresis loop is approximately proportional to the square of the magnetic induction intensity.

For high-speed motors, the alternating frequency of the magnetic field in the stator core is relatively high, resulting in relatively large stator iron loss, which accounts for the main part of the motor loss. Therefore, reducing iron loss is a major measure to improve motor efficiency. As the frequency increases, the ratio of stator eddy current loss to iron loss gradually increases. In summary, we should choose a silicon steel sheet with low core 
loss (core eddy current loss and core hysteresis loss) at high frequencies. For traditional non-oriented electrical steel, the thinnest grade is designed for high frequency applications. In this work, the motor design in this paper adopts 20PNF1500 electrical steel with low core loss under high frequency to design the high-speed motor stator. Figure 15 is the $\mathrm{BH}$ curve of 20PNF1500.

The core loss data of steel suppliers are almost all sine wave data, which can be characterized by the Steinmetz Equation (3) of hysteresis and eddy current loss [22]:

$$
P=C_{h} f B_{p k}^{n}+C_{e} f^{2} B_{p k}^{2}
$$

where $B_{p k}$ is the peak flux density in $\mathrm{T} ; f$ is the frequency in $\mathrm{Hz} ; C_{h}$ is the hysteretic return loss coefficient; $C_{e}$ is the eddy current loss coefficient. The index $n$ is usually assumed to be 1.6 1.8, but changes with $B_{p k}$. Since $n=a+b B_{p k}$, wherein $a$ and $b$ are both positive values, $n$ has a certain change. The unit of $P$ is usually $\mathrm{W} / \mathrm{kg}$.

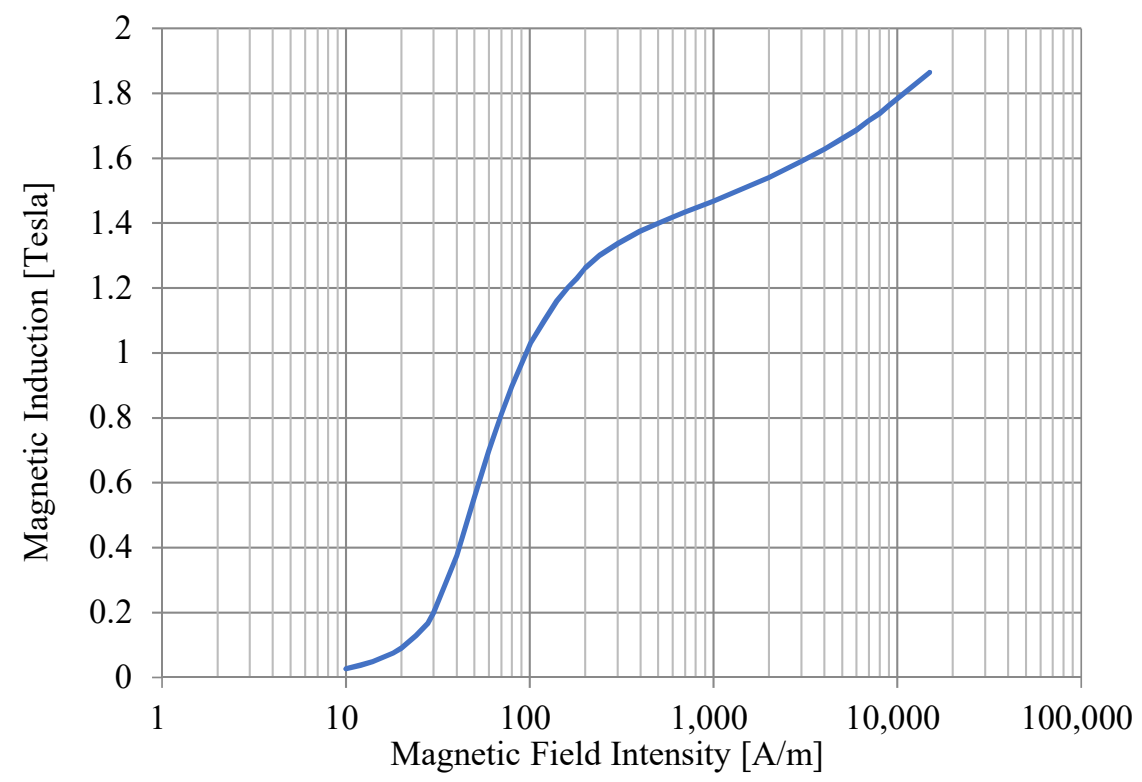

Figure 15. BH curve of 20PNF1500.

The magnetic flux density in the motor laminations may be far from sinusoidal. Therefore, the modified Steinmetz Equation (4) is used, which has the following form:

$$
P=C_{h} f B_{p k}^{a+b B_{p k}}+C_{e}\left[\frac{d B}{d t}\right]^{2}
$$

The hysteresis loss component is unchanged, but the eddy current component is proportional to the mean square value of $d B / d t$ in the fundamental frequency period. Eddy current loss coefficient $C_{e 1}$ can be modified from the sine wave coefficient $C_{e}$. If $B=B_{p k} \sin (2 \pi f t)$, then $d B / d t=2 \pi f B_{p k} \cos (2 \pi f t)$ and $(d B / d t)^{2}=4 \pi^{2} f^{2} B_{p k}{ }^{2} \cos ^{2}(2 \pi f t)$, and mean value $(d B / d t)^{2}=2 \pi^{2} f^{2} B_{p k}{ }^{2}$. For the sine wave magnetic flux density, the same result is given as Equation (5):

$$
C_{e 1}=\frac{C_{e}}{2 \pi^{2}}
$$

Using the above equations, the relationship between core loss and frequency of 20PNF1500 can be obtained, which is depicted in Figure 16.

Even when the permanent magnet rotor of a permanent magnet synchronous motor rotates freely, it will cause core loss in the stator core. The change in core loss with speed is shown in Figure 17, and the value of loss is listed in Table 5. 


\subsection{Rotor Eddy Current Loss}

High-speed permanent magnet synchronous motor stator slotting caused by air gap permeability changes, magnetic space harmonics caused by non-sinusoidal windings and current time harmonics generated by PWM power supply will produce large eddy current losses in the rotor. Due to the poor heat dissipation conditions of the rotor, excessive rotor eddy current loss will cause the rotor temperature rise to be too high. Excessive temperature causes the performance of the motor to decrease and even causes the permanent magnets to demagnetize. Therefore, the accurate calculation of rotor eddy current loss is of great significance to the improvement of motor performance and reliability.

Usually, there are two calculation methods for permanent magnet synchronous motor rotor eddy current loss: analytical calculation method and finite element method. The analytical method can quickly and intuitively reveal the essence of the problem and can well estimate the eddy current loss of the rotor in the motor design stage. The physical model established by the finite element method is closer to reality than the analytical method. The calculation accuracy is higher than the analytical method. Figure 18 shows the finite element simulation results of rotor eddy current loss.

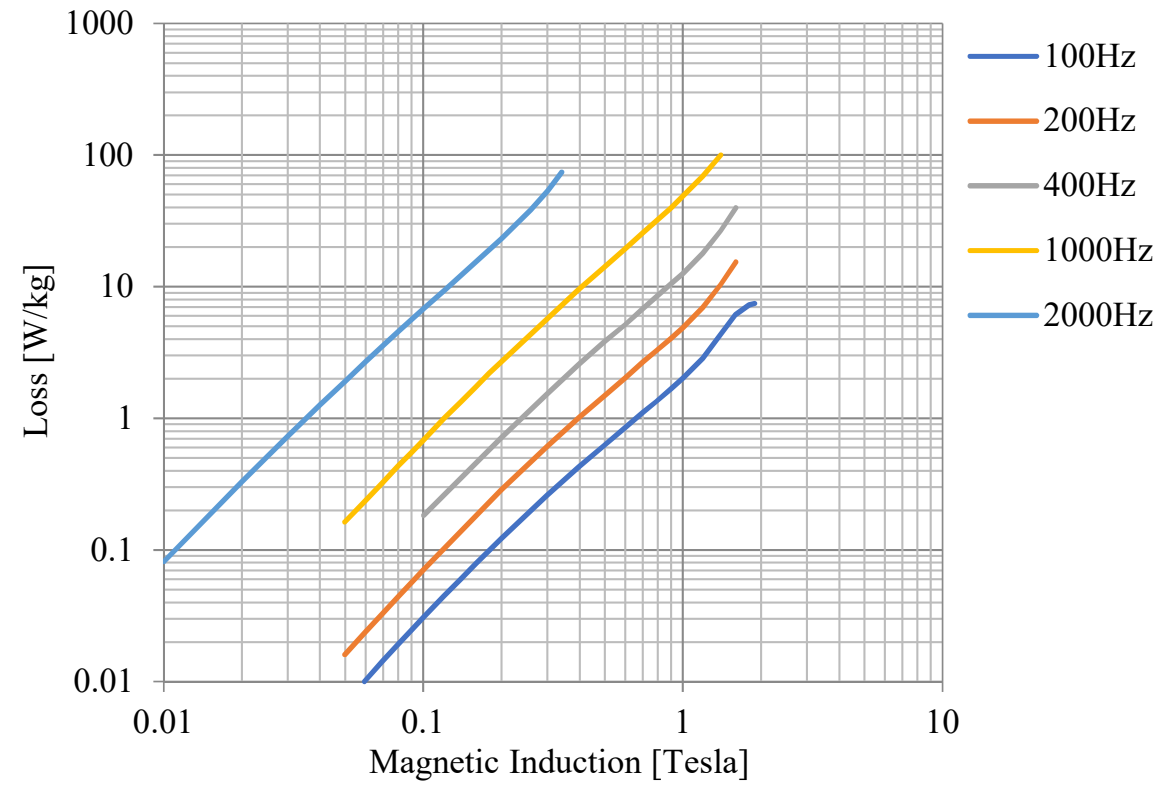

Figure 16. The relationship between core loss and frequency of 20PNF1500.

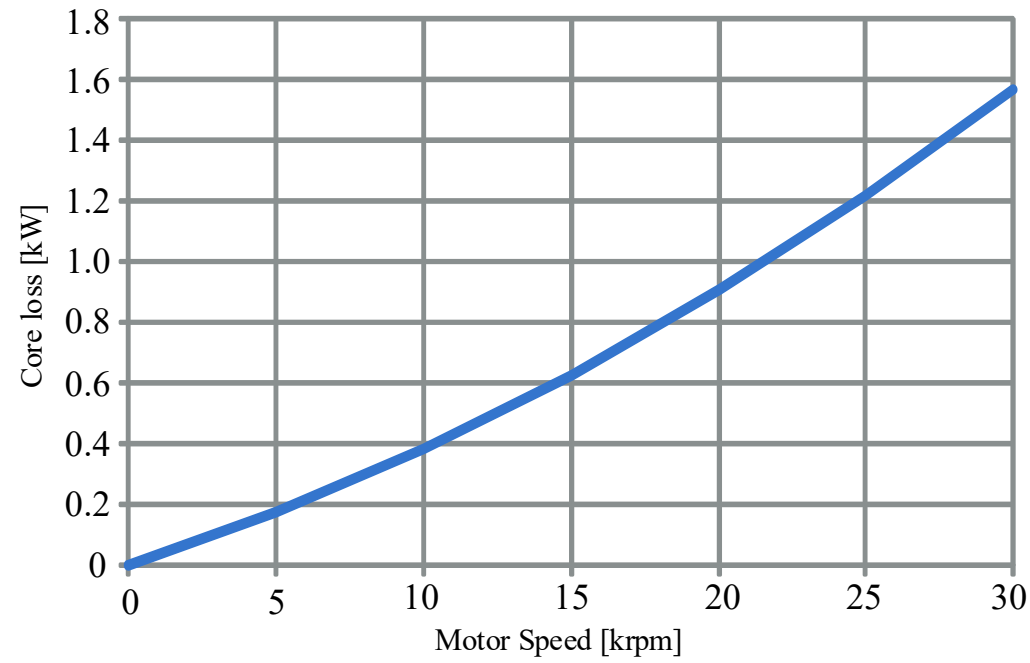

Figure 17. Core loss vs. speed change graph. 
Table 5. Core loss and speed change.

\begin{tabular}{ccccccc}
\hline $\mathbf{k r p m}$ & $\mathbf{5}$ & $\mathbf{1 0}$ & $\mathbf{1 5}$ & $\mathbf{2 0}$ & $\mathbf{2 5}$ & $\mathbf{3 0}$ \\
\hline $\mathrm{kW}$ & 0.18 & 0.39 & 0.63 & 0.91 & 1.22 & 1.57 \\
\hline
\end{tabular}

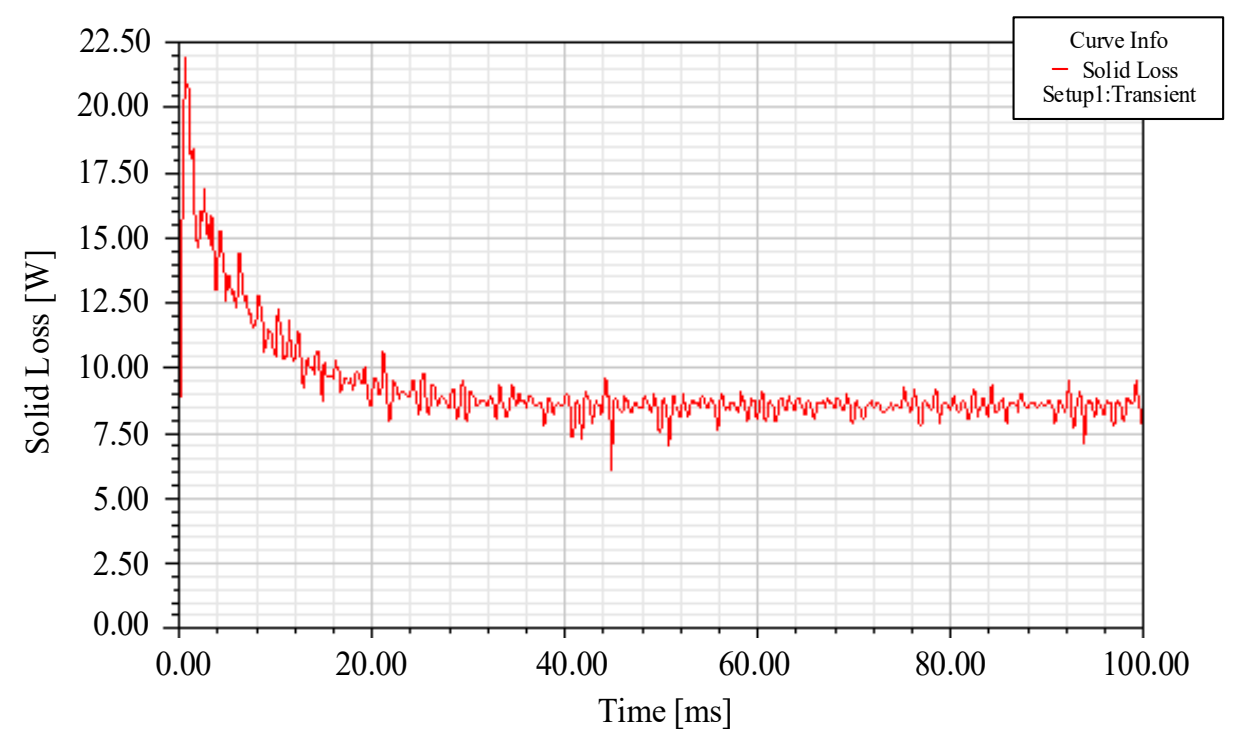

Figure 18. Rotor eddy current loss.

\subsection{Other Losses}

Other losses mainly include air friction losses and stray losses. Air friction loss is mainly caused by the mutual friction between the rotor and the surrounding air. Air friction loss is related to the rotor surface structure, surface roughness, motor speed, air density, air velocity, air radial pressure and other factors. Without the derivation process, it can be expressed as [23]:

$$
P_{\text {air }}=k C_{f} \pi \rho \omega^{3} r^{4} l
$$

in which $k$ is the surface roughness coefficient of the rotor (smooth rotor surface $k=1$ ); $\rho$ is the air density; $C_{f}$ is the coefficient of air friction; $\omega, r$ and $l$ are the angular velocity, radius and axial length of the rotor, respectively. Using Equation (6), the steady-state power consumption curve under air and rough vacuum can be calculated, which is illustrated as the green and blue line in Figure 19, respectively.

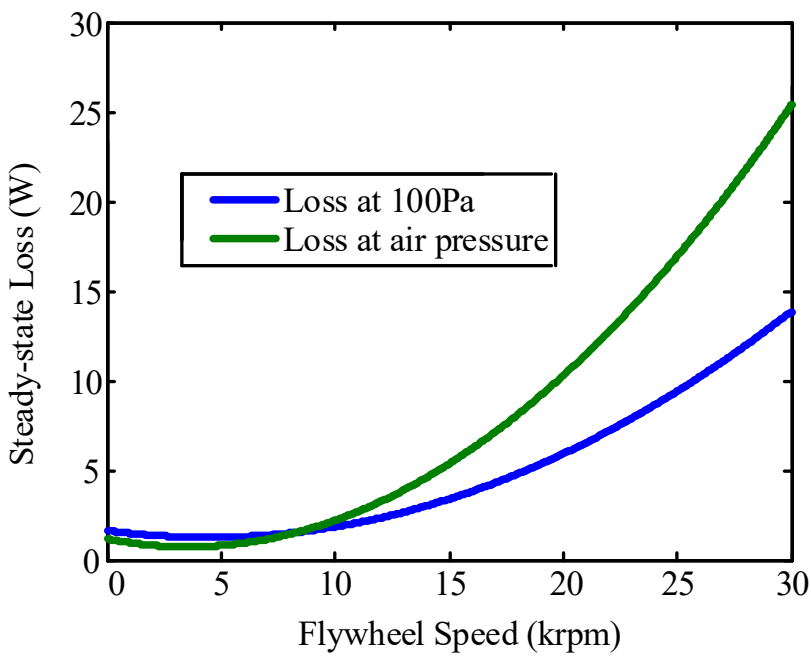

Figure 19. Steady-state power consumption curve under air and rough vacuum. 
The most effective way to reduce air friction loss is to increase the degree of vacuum in the flywheel housing. As shown in Figure 19, it is found that as the rotation speed increases, increasing the vacuum degree effectively reduces the steady-state power consumption of the motor. Generally, the method to reduce friction loss is to use high vacuum sealing means to prevent air leakage, control the distance between the outer circle of the flywheel rotor and the inner wall of the cavity to improve the pressure in the cavity and minimize the surface roughness as much as possible to make the rotor surface smooth.

The research results show that through the analysis of the electromagnetism, mechanical and loss of the motor, the output power of the motor reaches more than $300 \mathrm{~kW}$, and the specific power reaches $5000 \mathrm{~W} / \mathrm{kg}$. Additionally, through a series of measures to reduce the core loss, the simulation results show that the core loss at the rated speed is only $1.57 \mathrm{~kW}$. The current of the motor running at no load is very small, and the resistance is not large. Therefore, copper consumption only accounts for a small percentage. Therefore, the no-load loss of the motor does not exceed $2 \mathrm{~kW}$, which can satisfy the long-term stable operation of the flywheel.

\section{Conclusions}

This paper takes the low-loss, high-power, high-speed permanent magnet synchronous motor used in the magnetically levitation flywheel energy storage system as the research object and conducts research on the electromagnetic design, mechanical design, loss analysis and other key technologies of high-speed permanent magnet synchronous motor. The winding loss, core loss, rotor eddy current loss and mechanical loss of the high-speed permanent magnet synchronous motor are analyzed and optimized. By optimizing the design of the windings and placing the wires as close to the bottom of the slot as possible, the winding loss caused by the skin effect and proximity effect of the high-speed motor in the windings is reduced. The paper analyzes the influencing factors and calculation methods of core loss and reduces core loss by adopting Pohang Steel's 20PNF1500 with good core loss performance under high frequency and multi-layer thin silicon steel sheet lamination. This paper analyzes the eddy current loss of the permanent magnets of the rotor and verifies the feasibility of designing the whole permanent magnet excitation for high-speed operation. The use of magnetic bearing technology almost eliminates mechanical friction loss. The main factor of mechanical loss during high-speed operation-the influencing factor of air friction loss-is analyzed, and the loss is limited by increasing the vacuum degree in the flywheel housing. Finally, through the above series of analysis and design, the loss of the high-speed permanent magnet synchronous motor was reduced, and the loss reached the expected goal.

Author Contributions: Conceptualization, W.J.; methodology, F.N.; software, D.G.; validation, W.J.; formal analysis, F.N.; investigation, Q.L.; resources, D.L.; data curation, Q.L.; writing—original draft, W.J.; writing-review and editing, F.N.; visualization, D.G.; supervision, S.L.; project administration, D.G.; funding acquisition, F.N. All authors have read and agreed to the published version of the manuscript.

Funding: This research was funded by the National Natural Science Foundations of China under Grant 51907143, 52072269.

Institutional Review Board Statement: Not applicable.

Informed Consent Statement: Not applicable.

Data Availability Statement: Not applicable.

Conflicts of Interest: The authors declare no conflict of interest. 


\section{References}

1. Dai, X.; Wei, K.; Zhang, X.; Jiang, X.; Zhang, K. A review on flywheel energy storage technology in fifty years. Energy Storage Sci. Technol. 2018, 7, 765-782.

2. Arani, A.K.; Karami, H.; Gharehpetian, G.B.; Hejazi, M.S.A. Review of flywheel energy storage systems structures and applications in power systems and microgrids. Renew. Sustain. Energy Rev. 2017, 69, 9-18. [CrossRef]

3. Faraji, F.; Majazi, A.; Al-Haddad, K. A comprehensive review of flywheel energy storage system technology. Renew. Sustain. Energy Rev. 2017, 67, 477-490.

4. De Andrade, R.; Sotelo, G.G.; Ferreira, A.C.; Rolim, L.G.; da Silva Neto, J.L.; Stephan, R.M.; Suemitsu, W.I.; Nicolsky, R. Flywheel energy storage system description and tests. IEEE Trans. Appl. Superconduct. 2007, 17, 2154-2157. [CrossRef]

5. Tenconi, A.; Vaschetto, S.; Vigliani, A. Electrical machines for highspeed applications: Design considerations and tradeoffs. IEEE Trans. Ind. Electron. 2014, 61, 3022-3029. [CrossRef]

6. Bao, H.; Liang, P.; Chai, F. Key Technology of high speed permanent magnet synchronous motors for FESS. Micromotors 2014, $47,64-72$.

7. Shen, J.; Qin, X. High-speed permanent magnet electrical machines-Applications, key issues and challenges. Trans. Electr. Mach. Syst. 2018, 2, 23-33. [CrossRef]

8. Zhong, L.; Rahman, M.F.; Hu, W.Y.; Lim, K.W. Analysis of direct torque control in permanent magnet synchronous motor drives. IEEE Trans. Power Electr. 1997, 12, 528-536. [CrossRef]

9. Bon-Ho, B.; Seung-Ki, S.; Jeong-Hyeck, K.; Ji-Seob, B. Implementation of sensorless vector control for super-high-speed PMSM of turbo-compressor. IEEE Trans. Ind. Appl. 2003, 39, 811-818. [CrossRef]

10. Garcia, X.D.; Zigmund, T.B.; Terlizzi, A.; Pavlanin, R.; Salvatore, L. Comparison between FOC and DTC strategies for permanent magnet synchronous motors. Adv. Electr. Electron. Eng. 2011, 5, 76-81.

11. Nagorny, A.S.; Dravid, N.V.; Jansen, R.H.; Kenny, B.H. Design Aspects of a High Speed Permanent Magnet Synchronous Motor/Generator for Flywheel Applications. In Proceedings of the IEEE International Conference on Electric Machines and Drives, San Antonio, TX, USA, 15 May 2005.

12. Tao, D.; Zhou, K.; Lv, F.; Dou, Q.; Wu, J.; Sun, Y.; Zou, J. Magnetic field characteristics and stator core losses of high-speed permanent magnet synchronous motors. Energies 2020, 13, 535. [CrossRef]

13. Zhang, F.; Du, G.; Wang, T.; Wang, F.; Cao, W.; Kirtley, J.L. Electromagnetic design and loss calculations of a 1.12-MW high-speed permanent-magnet motor for compressor applications. IEEE Trans. Energy Convers. 2015, 31, 132-140. [CrossRef]

14. Li, Y.; Zhu, C.; Wu, L.; Zheng, Y. Multi-objective optimal design of high-speed surface-mounted permanent magnet synchronous motor for magnetically levitated flywheel energy storage system. IEEE Trans. Magn. 2019, 55, 1-8. [CrossRef]

15. Du, G.; Xu, W.; Zhu, J.; Huang, N. Power loss and thermal analysis for high-power high-speed permanent magnet machines. IEEE Trans. Ind. Electron. 2019, 67, 2722-2733. [CrossRef]

16. Zhang, Y.; McLoone, S.; Cao, W.; Qiu, F.; Gerada, C. Power loss and thermal analysis of a MW high-speed permanent magnet synchronous machine. IEEE Trans. Energy Convers. 2017, 32, 1468-1478. [CrossRef]

17. Xu, P.; Shi, K.; Sun, Y.; Zhua, H. Effect of pole number and slot number on performance of dual rotor permanent magnet wind power generator using ferrite magnets. AIP Adv. 2017, 7, 056631. [CrossRef]

18. Schneider, T.; Petersen, J.; Binder, A. Influence of Pole Pair Combinations on High-Speed Bearingless Permanent Magnet Motor Performance. In Proceedings of the 2008 4th IET Conference on Power Electronics, Machines and Drives, York, UK, 2-4 April 2008; pp. 707-711.

19. Tang, R. Modern Permanent Magnet Machines: Theory and Design; Mechanical Industry Press: South Norwalk, Connecticut, 2016. (In Chinese)

20. Gerada, D.; Mebarki, A.; Brown, N.L.; Gerada, C.; Cavagnino, A.; Boglietti, A. High-speed electrical machines: Technologies, trends, and developments. IEEE Trans. Ind. Electron. 2013, 61, 2946-2959. [CrossRef]

21. Huang, Y.; Dong, J.; Zhu, J.; Guo, Y. Core loss modeling for permanent-magnet motor based on flux variation locus and finite-element method. IEEE Trans. Magn. 2012, 48, 1023-1026. [CrossRef]

22. Li, J.; Tarek, A.; Charles, R.S. Improved Calculation of Core Loss with Nonsinusoidal Waveforms. In Proceedings of the Conference Record of the 2001 IEEE Industry Applications Conference, 36th IAS Annual Meeting (Cat. No. 01CH37248), Chicago, IL, USA, 30 September-4 October 2001; IEEE: Piscataway, NJ, USA, 2001; pp. 2203-2210.

23. Huang, Z.; Fang, J.; Liu, X.; Han, B. Loss calculation and thermal analysis of rotors supported by active magnetic bearings for high-speed permanent-magnet electrical machines. IEEE Trans. Ind. Electron. 2016, 63, 2027-2035. [CrossRef] 